\title{
Reading the World: Toward a Praxis of Inquiry, Critical Literacy and Cultural Knowledge
}

\section{Lasana Kazembe, Ph.D.}

Immersion into the world of inquiry, critical literacy, and cultural knowledge can be both challenging and intimidating. This is especially so when learners are expected to confront and grapple with ideas and conversations that may involve the complexities of power, gender, race, class, and other phenomena. These issues are bracketed by the ways in which educational and social institutions condition and shape learning and understanding. Within this context, a major responsibility of adult literacy educators is to locate and/or create openings in curricula and conversation that can positively impact pedagogical value, instructional goals, and academic learning.

In this article, I share my design of a course for a graduate school cohort of twenty early/mid-career law enforcement personnel from a large metropolis. Among the core learning outcomes was for students to develop and expand their knowledge base, critical function, and cultural literacy framework(s) in tandem with interrogation of the political and sociocultural context of education and society. This involved serious engagement, interrogation, and synthesis of diverse perspectives, ideas, and cultural frameworks - including one's own cultural group. A propensity for exploring context, posing difficult questions, framing argument, and intellectual deliberation were highlighted as aspects and cognitive practices of culturally literate persons.

This article opens by summarizing my experience with the cohort. Next, I discuss challenges encountered as students strove to acquire and deepen understandings of culture and its impact on domains of identity, knowledge, education, and power. Finally, I present specific strategies I used to promote critical pedagogy, inquiry, and practices to support critical literacy, knowledge diversity, and development of criticalist stances among learners. 


\section{Course Objectives: Culture, Education, and Power}

For adult literacy educators, a primary area of pedagogical concern is to encourage a critical, scholarly disposition among learners. This involves the cultivation of specific methods for reading, interpreting, synthesizing, and sharing ideas. For my students, this course was their first experience with critical theorizing, writing, and discourse around culture, education, and schooling. A major learning outcome was to promote the development of critical understanding of the concept of culture and cultural institutions (ex., schools, universities, police departments) within the context of multiculturalism, political economy, and urban education. I encouraged students to analyze the meaning(s), of culture; how it is manufactured, reproduced, and consumed. Within that context, we examined how relations of power, knowledge, social identity, and policy within educational institutions are conditioned and shaped by practice which, in turn, shapes the internal function and purposes of institutions.

The cohort was comprised of veteran law enforcement personnel who have spent decades doing police work in a large city. As is widely known (and written about), modern American policing is beset with broad and acute challenges, as well as frequent critiques of its institutional policies, procedures, and practices. The relationship between police and public has been put to the test, especially during the last $20-30$ years. Shootings by the police of people of color, growing militarization of local police forces, expansion of the surveillance state, and the erosion of civil liberties are perceived by many as chief issues framing the critique of modern policing. Expectedly, the cohort was aware of those critiques, and brought their own [complimentary and contradictory] perspectives into classroom discussions and academic writings. It should be noted that the cohort was a diverse group comprised of white men (6), Black men (3), Latino men (5), and Black women (5). Given the context of our course, our conversations were frequently bracketed by analyses and observations around race(ism), poverty, crime, and violence. 


\section{Having Difficult Conversations}

Another daunting challenge faced by adult educators is dealing with the predispositions of adult learners. If not properly framed, conversations involving issues such as race, crime, violence can often devolve into reductive, ineffective exercises, or conjecture-laced shouting matches. In such instances, intellectual outcomes can become lost or muddled, and participants robbed of the opportunity to explore viewpoints, expand and deepen cultural knowledge, and co-construct valuable dialogue. The conceptual and racial framework of our class made it unrealistic to expect to avoid conversational tensions. Instead, I encouraged the students to see these tensions as opportunities (gateways) to more fully engage and interrogate the political and cultural context of ideas, to interrupt fixed notions, and to resist the pull toward easy assumptions.

Our class conversations were structured to address broad factors (cultural, economic, social, political) framing the ecological contexts in which education is engaged, particularly in urban settings. As observed throughout the course, several factors made this challenging task even more challenging including the cohort's:

- $\quad$ status as veteran law enforcement personnel;

- limited and/or lack of experience with grappling with the intersectionalities and specific ecological contexts informing race, culture, education, pedagogy, etc.;

- individual and/or collective views which may have been inhibited by emotionalism, stereotypes, inherited notions, implicit biases, media characterizations, illogical fallacies, personal encounters, etc. which shaped subjectivities, fears, peer acceptance, and the need to think/believe in conformist ways.

Taken together, these factors might have resulted in an educational experience that was stifling, accusatory, and reactionary. However, the majority of the cohort consistently demonstrated a willingness to present and have their views challenged, to proactively engage ideas which challenged and/or unseated fixed notions, and to wrestle with dogged questions. The cohort also belonged to a community of law enforcement professionals charged with upholding the Constitution and adhering to a uniform chain of command. As such, their engagement with text, 
classroom conversations, and a course framework which encouraged them to question, challenge assumptions, and (re)interpret ideas resulted in a more meaningful educational experience.

\section{Examining Strategy: Moving Toward a Praxis of Inquiry and Critical Literacy}

An important, practical component of adult literacy instruction involves linking course learning outcomes to broader academic outcomes and to the real world. Beyond merely acquiring knowledge and trafficking in discourse, as potential future educators, students were encouraged to be introspective and to take a criticalist stance. I encouraged students to examine the implications and value of viewing themselves as curriculum-makers who exercise agency in understanding, interpreting, constructing, and transforming curricula, and themselves.

\section{Intentionally Selected Texts}

From the beginning, I encouraged scrutiny of culture as a site of human struggle. To achieve that objective (and not risk alienating adult learners' voices), it was imperative that careful thought be applied to the selection of texts for the course. The majority (over 98\%) of texts I selected for the course were authored by white male authors. And, while only 1-2 of those authors would be considered progressive, the texts of the other white male authors were used to bracket dialogue and writing around themes explored in the course. Two additional points about the literature and to our course objectives are important to consider. The first point is what we read; the second point is how we read. For example, while certain texts offered overt critiques of racism, social inequities, and militarism, other texts were less subjective, and therefore, challenged students to develop their own critical stance.

Throughout our course, students were challenged to engage the ideas of critical voices in the fields of education, sociology, and political science. In our analysis of schooling, education policy, democracy, and authoritarianism, we consulted the work of Henry Giroux (2015). C. Wright Mills' work (2000) informed and guided our interrogation of the interwoven apparatuses of corporate, military, and political centers within society. Mills' ideas also served as a 
foundation and springboard for discourse and writing around the concept, role, and social cost of citizenship, individuality, and freedom. The writings of William Stern (1997), Randolph Bourne (1921), Angus McLinn (2012), and Ta-Nehisi Coates (2013) served as critical jump-offs into rich conversations about historical epochs of American society including: Progressive Era (18901920), Civil Rights (1944-1960), post-Civil Rights (1970s-1990s), and the contemporary era (1980s-present). During this leg of our intellectual journey, we explored Irish-American history, American multiethnic nationalism, cultural memory and remembrance, white supremacy, political economy, and inherent challenges of navigating within a highly-racialized political order, and its attendant institutional structures. Finally, students were introduced to and interrogated copious academic reports and government studies which discussed issues such as U.S. military expenditures, foreign policy, racial discrimination, bias, hyper-segregation, prison pipeline, terrorism, and globalization.

Throughout the course, several white males of Irish descent within the cohort responded favorably when our course readings explored the history of Irish Americans. My expectation was for the cohort (particularly white male students) to grasp the historical ecological context (i.e., political struggles, social inequities, ethnic solidarity, cultural resilience, transcendence) of marginalized Euro-Americans, so that they might be more inclined to broaden their understanding of the contemporary ecological context of marginalized groups (ex., African Americans, women, immigrants). I reasoned that the white males in the cohort might be less likely to resist engaging the ideas of white male writers. It was for this same reason that I selected only one Black author's work for the course.

Critical literacy is an approach to text that encourages readers to tease out underlying messages, challenge status quo assumptions, and connects the political to the personal and vice versa. Beyond mere reading, critical literacy seeks to foster an analytical attitude toward text and to encourage "social action through language" (Shor, 1999). In keeping with this approach, I would often tell students: "We are in the idea business." I used this rhetorical 
strategy to center debate, diffuse classroom tension, and promote adherence to the broader philosophical aims of the course. The potentially controversial nature of certain themes explored in the course sometimes led to flared tempers, over-talking, predisposition, charges of racism, or worse - silence. None of those postures served our instructional outcomes. While spirited debate was heartily encouraged, the adult learners were reminded often to connect their observations and commentary to ideas within the text, and to avoid collapsing conversations into personal or emotion-fueled invective.

To further encourage students to take the high road during discussions, I stressed to the cohort to always consider context when framing and presenting their analyses. That is to say, I encouraged students to resist the trap of rhetorical singularity, and to instead, base their (re)interpretations using a systems analysis. Such considerations were (pr)offered in order to facilitate expanded world views, as well as encourage the growth of cultural competencies, appreciation for alternative views, and multidirectional thinking.

Seeing the Deep More Deeply

For many, the history of the economic, social, and class struggles of European settlers (particularly Irish) to America is a story of transcendence, resilience, and cultural transformation. Thus, the cohort was given an immersion into the social history of Irish Americans as a means of inviting broader dialogue around prejudice, discrimination, and othering. Relatedly, the deliberate historicizing of readings and discourse about Irish social history served as an intellectual inroad to more expansive conversations about cultural memory, epistemology, transcendence, and social justice. In a specific, recurring example, the cohort learned about the Catholic archbishop of New York, Father John Joseph ‘Dagger John' Hughes (1842-1864), who had gained prominence for his political activism, anti-poverty crusades, and social entrepreneurship among New York's masses of poor Irish immigrants. Hughes encouraged firstgeneration Irish Americans to draw on their culture and transcendent folk traditions to create institutions dedicated to improving and transforming the economic and social conditions of poor 
and Irish Americans. On multiple occasions, I referenced the work of Father Hughes in broader conversations around contemporary struggles of poor, working-class, and marginalized populations.

\section{Linking the Past and Present}

The cohort was introduced to the idea of metanarrative. As a singular, totalizing account, a metanarrative serves a particular political and cultural expediency. As Lyotard (1984) and others have described, one of the key functions of metanarrative is to legitimize power and authority. I routinely challenged students to analyze the inconsistency and political expediency of historical remembering. Students were routinely asked to think about why it is acceptable (and in some cases, expected) for certain histories (ex. WWII, Founding Fathers, Bunker Hill) to be remembered? Similarly, why does the remembering of other histories (ex., Transatlantic Slave Trade, Jim Crow) conjure hostility and controversy? To further unpack metanarrative, we engaged critical conversations that explored the role of "official" story vis-à-vis the dialectics of patriotism and sports, race and schooling, and fact and belief. The cohort was encouraged to invoke problem-posing questions and historical synthesis as a means of challenging and critically resisting metanarrative. This practice served as an effective learning modality to motivate students toward cultural competence, critical inquiry, and deep questioning.

\section{Conclusion}

The question of how to immerse older learners into the rigors of inherent in cultural literacy studies has been a persistent challenge. A related challenge involved the ways and means of how curriculum and instruction might be presented in order to encourage learners to actively contribute to a community of discourse. Another pedagogical challenge was how to design and facilitate the course with an instructional framework which promoted learning that was "active, strategic, self-conscious, and purposeful" (Brown, 1994). Compounding those challenges was the added difficulty of engaging in constructive conversations and cognitive practices involving race, inequality, and social conditions shaped by broader cultural and political dynamics. The 
cohort was challenged to problematize questions about the philosophy and function of education as a means of assisting them with developing a criticalist, praxis-orientated stance. Such a task required deep analysis of culture, cultural processes, social relations, ideation, political economy, and the role of institutions in influencing and shaping human thought and behavior.

This paper described the outline of a graduate school class for a cohort of law enforcement personnel as they experienced a course dealing with education, culture, and power. The strategic pedagogical approaches I undertook in this course sought to enhance these students' capacities for critical literacy, cultural competence, and contextual understanding of ecological systems. Encouraging critical, scholarly dispositions and exploring fixed cultural assumptions among learners is foundational work for all adolescent and adult literacy educators. 


\section{REFERENCES}

Bourne, R. (1916) Trans-national America. Atlantic Monthly, Retrieved from: https://www.theatlantic.com/magazine/archive/1916/07/trans-national-america/304838

Brown, A. (1994) The advancement of learning. Educational Researcher, 23(8), 4-12.

Coates, T. (2013). The ghetto is public policy. The Atlantic, Retrieved from: https://www.theatlantic.com/national/archive/2013/03/the-ghetto-is-public-policy/274147

Gilens, M., \& Page, B. (2014). Testing theories of American politics: Elites, interest groups, and average citizens. Perspectives on Politics, 12(3), 564-581. doi:10.1017/S1537592714001595

Giroux, H. A. (2015). Dangerous thinking in the age of the new authoritarianism. New York, NY: Routedge.

King, J. E. (2004). Culture-centered knowledge: Black studies, curriculum transformation, and social action. In J. A. Banks \& C. A. McGee Banks (Eds), Handbook of research on multicultural education (2nd ed., pp. 349-378). San Francisco, CA: Jossey-Bass.

Lyotard, Jean-François. (1984) The postmodern condition: A report on knowledge. Minneapolis: University of Minnesota Press. Reprint 1997. Translated by Geoff Bennington and Brian Massumi.

McLinn, A. (2012). Struggling to come to terms with the past. Liberator Magazine, Retrieved from http://weblog.liberatormagazine.com/2012/12/struggling-to-come-to-terms-withpast.html

Mills, C. W. (2000). The power elite. United Kingdom: Oxford University Press.

Shor, I. (1999)) What is critical literacy. The Journal of Pedagogy, Pluralism and Practice, 1(1).

Stern, W. J. (1997). How Dagger John saved New York's Irish. City Journal, Retrieved from: https://www.city-journal.org/html/how-dagger-john-saved-new-york's-irish-11934.html 